Revista de Filología Románica

ISSN: 0212-999X

http://dx.doi.org/10.5209/RFRM.58357

\title{
La representación de la isla de Chipre y su conversión en un espacio hostil en Relacion de la Guerra de Cipre y sucesso de la batalla naual de Lepanto (1572) de Fernando de Herrera
}

Silvia-Alexandra Ștefan ${ }^{1}$

Recibido: 15 de enero de 2017 / Aceptado: 6 de septiembre de 2017

Resumen. Fernando de Herrera escribe y publica la Relación en 1572, habiendo pasado menos de un año de la famosa victoria de Lepanto de don Juan de Austria en contra de la flota de galeras otomanas, del 7 de octubre de 1571. Su relación, histórica y a la vez ficticia por el ímpetu propagandístico y subjetivo de su autor, que nunca salió de su ciudad natal de Sevilla, promociona una visión correspondiente de la isla de Chipre, inicialmente vista desde la perspectiva de su fama como la "más dichosa" del Mediterráneo y "consagrada a Venus", y posteriormente representada como espacio hostil, tras la caída de Famagusta en las manos del poder turco. El presente trabajo se propone reflexionar sobre los elementos que, reunidos, suman tal conversión de la representación de la isla y de sus habitantes, así como se desprende de la relación herreriana.

Palabras clave: Renacimiento español; humanismo sevillano; ideología imperial; épica histórica; verdad y verosimilitud.

[en] The Representation of the Island of Cyprus and its Conversion into a Hostile Space in Relacion de la guerra de Cipre y sucesso de la batalla naual de Lepanto (1572) by Fernando de Herrera

\begin{abstract}
Fernando de Herrera wrote and published his Relación in 1572, after having passed less than one year since don Juan de Austria had achieved the famous victory of Lepanto against the Ottoman fleet of galleys, on $7^{\text {th }}$ October 1571. Herrera's account, at once historical and fictitious, due to its author's propagandistic and subjective impetus, promotes a correspondent view on the island of Cyprus, initially seen from the perspective of its fame as "the most blissful" of the Mediterranean and "consecrated to Venus", and subsequently represented as a hostile space, because of the fall of Famagusta under the Turkish power. The current paper aims at reflecting upon those elements that, reunited, sum up to such conversion of the representation of the island and its inhabitants, as it is being portrayed in the Herrerian account.
\end{abstract}

Keywords: Spanish Renaissance; Sevillian Humanism; imperial ideology; historical epic; truth and verisimilitude.

Cómo citar: Ștefan, S.-A. (2017). La representación de la isla de Chipre y su conversión en un espacio hostil en Relacion de la Guerra de Cipre y sucesso de la batalla naual de Lepanto (1572) de Fernando de Herrera, en Revista de Filología Románica 34.2, 371-377.

1 Dpto. de Lingüística Románica, Lenguas y Literaturas Iberorománicas e Italiano. Universidad de Bucarest.

E-mail: silvia.stefan@1ls.unibuc.ro 
Cuenta la leyenda que la isla de Chipre es la isla del amor y de la hermosura. La famosa Petra tou Romiou sigue atestiguando el lugar de nacimiento de Afrodita, de la espuma del mar y la conocidísima historia de que la diosa fue posteriormente llevada hasta la superficie dentro de una enorme concha marina, tal y como viene retratada en el espléndido cuadro que Sandro Botticelli pintó en 1485.

Durante el Renacimiento, en la península ibérica la isla mediterránea sigue asociada a Venus, a la que Juan de la Cueva llama «diosa de Chipre» (Cueva 2008[1581]: 46) en boca de Dios del Sueño, personaje de su comedia El Infamador, publicada en 1581. Cuarenta años antes, Juan de Arce de Otárola la menciona también como lugar ameno en sus Coloquios de Palatino y Pinciano de 1550. En el diálogo de los dos estudiantes salmantinos, al preguntarle Palatino cuáles son las condiciones de Venus para los enamorados, le contesta Pinciano reforzando la analogía entre la diosa Venus y la isla de Chipre, su lugar de nacimiento, y por ende isla del amor y de la hermosura e hipóstasis perfecta del antológico tópico de la literatura medieval y renacentista del locus amoenus. Así pues, cuenta Pinciano que a Venus:

entre los elementos la sigue el aire y el espuma del agua, de donde ella dicen que nació, y entre los humores la flema con sangre, y entre los sabores lo dulce; entre los metales la plata; entre las piedras el coral y cornerina y las de colores varios y hermosos; entre las flores el jazmín, las rosas y todas las otras flores agradables; entre las yerbas, las violetas y valariana y sándalo; entre los árboles los granados, que dicen los poetas que los plantó la diosa Venus en Cipre; entre las aves, las más enamoradas, y especialmente la golondrina y el aguanieve y el águila, que los egipcios llaman venus, que dicen que es tan enamorada y lasciviosa que nunca la llama el macho que no la obedezca. Entre los peces también son venéreos el cancro, que pelea por el marido, y las merulas y otros tales; entre los animales, los más amorosos y fecundos, especialmente las cabras, que dicen que de siete días nacidas conciben y engendran; entre los hombres, todos los blandos y amorosos y delicados y enamorados. (Arce de Otárola 1995 [1550]: vol. II, 989).

La identificación de Afrodita con la isla de Chipre hace posible la transferencia de las cualidades con las que normalmente se le juzga a la diosa hacia la isla misma y por supuesto hacia sus habitantes.

Esta imagen idílica de Chipre no se debe ni muchísimo menos a un total desconocimiento de la isla por parte de los españoles. Todo lo contrario, las relaciones comerciales y políticas entre Cataluña y Aragón y las islas del Mediterráneo incluyen una larga historia de intercambios comerciales, establecidas a partir de las cruzadas, y también varias alianzas nupciales entre Chipre y Aragón a lo largo del siglo XIV.

Tampoco podría ignorarse el hecho de que, hasta la invasión de Chipre por los Mamelucos en 1426, los piratas catalanes durante el siglo XV usaron Chipre y Rodas como bases para sus incursiones contra Egipto y Siria musulmanas, incursiones después de los cuales centenares de cautivos vendidos en Chipre como esclavos se iban a trabajar en las plantaciones de azúcar de la isla.

Y asimismo, hay que tomar en cuenta las memorias de viaje de los que partían en peregrinaje hacia Jerusalén, en donde se menciona la isla de Chipre como punto de parada, justo antes de entrar en Siria, para los peregrinos que querían ver la capilla de la Cruz del ladrón bueno. Se supone que se trata de la capilla de San Bernabé cerca 
de Salamina, atestada desde el año 433, en donde a menudo se cantaba la misa compartida entre un peregrino del Occidente latino y un fraile griego chipriota.

Así las cosas, las relaciones entre la isla de Chipre y el resto del Mediterráneo son por ende bastante potentes y se consolidan aún más una vez que Chipre es anexionada a la República Veneciana en 1473. Un siglo más tarde, tras el cerco de Famagusta de 1570, los venecianos son expulsados de la isla, que viene a ser ocupada durante tres siglos por los otomanos. Mientras tanto, los griegos de Chipre se refugiaban a España, la mayor potencia de Europa en la época. El mapa que Ortelius hizo en 1579 de la peregrinación de San Pueblo, que presta especial atención a las condiciones físicas del terreno y a los topónimos, nos aclara cómo se veía el mundo por aquel entonces, a la vez que es una buena indicación de la posición de la isla de Chipre en el siglo XVI.

El cerco de Famagusta de 1570, que iba a desencadenar la gran batalla del mar, de Lepanto, del 7 de octubre de 1571, es justo el momento descrito por Fernando de Herrera (1534-1597) en su Relacion de la guerra de Cipre y sucesso de la batalla naual de Lepanto, que se publica en Sevilla, en menos de un año de los acontecimientos históricos arriba mencionados, en el mes de septiembre de 1572.

Como se puede ver, el nombre de la isla de Chipre aparece desde el título, pues era vista como un lugar exótico y meollo del asunto del conflicto, a saber el quid de la cuestión histórica a tratar. La acostumbrada imagen paradisiaca viene reforzada desde el primer capítulo por Fernando de Herrera, subrayando la ubicación de Chipre cerca de Jerusalén, o la así llamada por los cristianos tierra firme. Según los avatares del género, Herrera proporciona una descripción geográfica, una descripción económica, una descripción del clima y de los habitantes de la isla y al final repasa la historia mítica de Chipre, anclando su origen en la época de los romanos.

Desde la perspectiva geográfica, la isla tiene, según Herrera, 430 millas y está riquísima en ciudades famosas, entre las cuales Famagusta, la posteriormente cercada, considerada como feria de toda la isla:

Está pues esta isla famosa entre todas las del mar, opuesta por el Setentrion a la Caramania, y de aquella parte está más cerca de tierra firme, que de otra alguna, por la vanda de Mediodia mira a la prouincia de Egipto. Y por el Leuante tiene a la Suria, bañando sus costas al mar de Panfilia por la buelta de Poniente. Su circuito abraça quatrocientas y treinta millas. Y antiguamente fue ínclita con quinze ilustres ciudades, y entre ellas eran celebradas y clarissimas Salamis y Pafo. La primera insine con los simulacros de Iupiter, y la otra con el templo de Venus. Pero las que en ella alcançan aora alguna claridad son pocas, como Nicosia cabeça de la isla, que era en otro tiempo Tremito y Tamasso, que es oy Famagosta, fortissima ciudad y nobilissimo puerto y feria de toda la isla. (Herrera 1572: Relación, cap. I)

La perspectiva económica sigue el topos de la riqueza paradisiaca de la isla, en donde se encuentran vino, aceite, ganado, metales, y que es muy frecuentada por los mercaderes, debido, de nuevo, a su cercanía a Siria:

Después de estas todos los demás lugares están maltratados y son de poca abitación. Y aunque en grandeza es inferior a Sicilia, Sardeña y Candia, en nobleza, virtud, fertilidad y abundancia, ninguna de las del Mediterraneo es más dichosa. Porque es fertil de vino y azeyte, (...) y es muy abundante de ganado y rica de 
metales, y otras cosas que pertenecen al vso vmano, por quien no menos, que por la oportunidad del puesto cercano a la Suria, es muy frequentada de mercaderes. Y assi no es necessitada de cosa estrangera, con solas sus fuerças proprias. (Herrera 1572: Relación, cap. I)

La descripción del clima y de sus habitantes ya introduce una anticipación proléptica de los infortunios del cerco de Famagusta y la ocupación posterior de la isla por los otomanos. En Chipre, cuenta Herrera, hay mucho calor y por lo tanto los habitantes no están acostumbrados a los ejercicios militares. Además, las mujeres son extremadamente lascivas, diríamos como raíz del vicio que traerá la guerra, pues, como explica Herrera más adelante en la parte histórica, Jacopo, rey de Chipre, es hijo ilegítimo, engendrado de adúltero ayuntamiento:

El ayre desta tierra no es bien sano, y es peligroso en el estio su demasiada calor, y los hombres que hazen aquí su abitación son delicados, y de mucho regalo, que no pueden sufrir alguna fatiga, ni durar en los trabajos, antes ocupados y entregados todos al deleyte y ocio, viuen de todo punto oluidados de los exercicios militares. Porque las mugeres son estremadamente laciuas desde sus primeros abitadores. Y de aquella fama nacio la fabula de ser cosagrada a Venus. (Herrera 1572: Relación, cap. I)

Sigue Herrera con la historia mítica de Chipre, desde la época de los romanos, diciendo al emplear el topos antiguo toto orbe cantabilis, el mundo entero lo canta, que las riquezas de la isla fueron antiguamente tan grandes que incluso el pueblo romano, vencedor de tantas gentes, se gloriaba de su integridad y justicia. Destacan como se puede ver dos epítetos, llamativos por su fuerza de rememoración paradisíaca, que repite a menudo Herrera en la descripción de la isla, de la que dice que es dichosa y riquísima.

En el segundo capítulo, como anticipamos, Herrera busca la raíz de la guerra en el carácter vicioso de sus habitantes y cuenta la historia del nacimiento de Jacopo, rey de la isla, de una relación adulterina. En 1458 muere el rey Juan de la familia francesa de los Lusignan, reinante de la isla, y su hija Carlota se casa con Ludovico, hijo del duque de Saboya. Jacopo, hermano de Carlota, es hijo ilegítimo de Juan, de hábito eclesiástico, y llega a ser rey, con la ayuda del Sultán de Egipto, en contra de Ludovico, esposo de Carlota.

Porque sabiendo Jacopo, que los Cipriotas pedían por su rey a Ludouico de Saboya, y lo esperauan, passó en Egipto, y suplicando vmilmente al Soldán que le fauoreciesse como a hijo de vn rey su amigo y tributario, fue por orden del Soldan jurado en Egipto por señor y rey de Cipre, y con la armada de aquel principe fue sobre la isla y se hizo rey, huyendo de su furor Ludouico en seguimiento de su muger Carlota. (Herrera 1572: Relación, cap. II)

Llegado rey, Jacopo se casa con Catalina Cornaro, hija de Marco Cornaro, gentilhombre veneciano. Jacobo muere doce años más tarde, dejando a la reina preñada con un hijo que murió también a unos pocos días de su nacimiento. Catalina Cornaro queda reina de la isla y, así las cosas, en 1473 los venecianos reivindican el reino de la isla: 
Y como en acidentes semejantes sucedā escādalos y dissensiones, haziēdo vn terrible tumulto los Cipriotas, y puesto el reyno en alboroto y armas, Pedro Mocenigo general de la armada Veneciana, q ala sazō se hallaua en Modō, nauego alla reduziēdo la isla a obediēcia de los Venecianos, por ser, como ellos dezian, justos erederos de su hija la reyna Catalina, porque el rey no se caso con ella como hija del Cornaro, sino de san Marco, atendiendo que la republica le señalo la dote. Pero el justo derecho q ellos tenian, era el de las armas, con que los poderosos hallā por suya toda justicia. Y persuadida la reyna de los Venecianos, se fue a biuir a Venecia, dexandoles libre la administracion de aquella isla. (Herrera 1572: Relación, cap. II)

Al mismo tiempo, como es obvio, los otomanos consideraban que la isla se les debía otorgar a ellos. Herrera explica de tal modo el conflicto entre los turcos y los venecianos, cada uno se consideraba heredero justo y verdadero dueño de Chipre:

El derecho de la qual pretendia el Soldan de Egipto, porque dezia que Cipre y Rodas tocaua a su imperio, por ser el señor de Ierusalen, de cuyo reyno piensan que son estas islas. Pero despues que el belicossisimo emperador Selin destruyo la potencia de los Mamelucos, y dio cruel y afrentosa muerte al grande y valiente Soldan Tomumbeyo, y se hizo señor de Egito y Suria, quedo en su casa el derecho de Cipre y Rodas. Y como Solimano su hijo intento, y consiguio la conquista de Rodas en el principio de su imperio, assi su nieto Selin pretendia como Rey de Egito y Jerusalen el reyno de Cipre. (Herrera 1572: Relación, cap. II)

Por tanto, cuenta Herrera en el cuarto capítulo de su Relacion, como Selim les pide a los Venecianos la isla de Chipre, como reyno que tocaua al Turco, amenazando con tomarla por voluntad propia de los venecianos o si no, por fuerza se la habían de entregar. Que les haría crudelísima guerra, sin algún género de piedad. A lo que los venecianos se negaron, diciendo que poseían justamente a Chipre. De esta suerte se declara la guerra. Herrera también comenta en el siguiente capítulo como los venecianos no cuidaban la isla, y que los cipriotas de hecho aborrecían el gobierno de los venecianos, a causa de sentirse opresos por ellos, y como no tenían nada en contra de probar nueva fortuna con señor nuevo, pensando que el Turco se contentaría con el imperio de la isla, dejándolos en sus ritos y libertad, como había hecho con otros muchos que le habían dado la obediencia. Anticipando la inmensa crueldad que iban a desencadenar el Sultán en contra de los líderes venecianos al vencer en Famagusta, puntualiza además Herrera que:

ninguno quería encender contra si el ayrado ánimo de aquel poderoso enemigo, que podía meter a hierro todos los hombres de aquel reyno y exercitar en ellos vn singular exemplo de crueldad inumana. (Herrera 1572: Relación, cap. V)

Mientras tanto, el Sumo Papa Pio V, hace la Liga Santa con Felipe II y los venecianos y empieza la campaña militar en el Mediterráneo. Los venecianos tienen orden a enfrentarse con los turcos, aún si no iban a encontrarse con las galeras españolas o las del Papa. En el capítulo IX se describe como los turcos ganan Nicosia, y en el $\mathrm{X}$ como la isla se convierte en un valle de las lágrimas, hic lacrimarum valle. En un típico discurso de lamentatio Herrera describe como los cipriotas echaban la culpa a 
los reyes cristianos, por su poca fe, lo que convierte la causa en motivación de una exhortatio para la causa de Cristo, la causa pública, de todos los cristianos. El drama de los cipriotas llega grandísima, adquiere proporciones consistentes y se convierte en el discurso herreriano en la causa de toda la oicumena cristiana. Lo que verdaderamente hizo temblar a todos fue el castigo que el Sultán le proporciono al general veneciano que dirigió la defensa, Marco Antonio Bragadino, que fue desollado y su piel llena de paja colgada en una vega del navío del capitán turco, Ali Pachá.

Hay quienes consideran que el horroroso acontecimiento del final del cerco de Famagusta, que retrata Herrera en la primera mitad de su Relacion, permaneció por mucho tiempo en la memoria de los cristianos. Por ende, fue ilustrado por Tiziano en su cuadro El desollamiento de Marsias, en donde se recoge la leyenda del dios Apolo y Marsias, que se enfrentaron en un concurso musical tomando las Musas por jueces. La representación pictórica tuvo el papel de hacer metafóricamente persistir en la memoria de la posteridad los desoladores hechos históricos que zarandearon los ánimos de sus contemporáneos occidentales y que convirtieron la representación de la isla de Chipre para los cristianos, desde su percepción como locus amoenus paradisíaco hasta su imagen de espacio hostil bajo poder otomano. Al final, por su hybris de haber desafiado a un dios, Marsias perdió la vida.

\section{Referencias bibliográficas}

Arce de Otárola, Juan de (1995 [1550]): Coloquios de Palatino y Pinciano. Ed. José Luis Ocasar Ariza. Madrid: Turner.

Barbero, Alessandro (2011): Lepanto. La batalla de los tres imperios. Traducción de Teófilo de Lozoya y Juan Rabasseda. Barcelona: Pasado y Presente. Original: Alessandro Barbero (2010): Lepanto. La bataglia dei tre imperi. Roma: Laterza.

Bennassar, Bartolomé (2004): Don Juan de Austria. Un héroe para un imperio. Madrid: Temas de Hoy.

Binotti, Lucia (2012): Cultural Capital, Language and National Identity in Imperial Spain. London: Tamesis.

Botella-Ordinas, Eva (2012): “'Exempt from time and from its fatal change’: Spanish imperial ideology, 1450-1700”. Renaissance Studies 26.4: 580-604.

Cueva, Juan de la (2008[1581]): El Infamador. Ed. Anthony J. Grubbs. Madison: University of Wisconsin.

Davis, Elisabeth (2001): "Myth and Identity in the Epic of Imperial Spain". Arizona Journal of Hispanic Cultural Studies 5: 257-259.

Gaylord Randel, Mary (1971): The Historical Prose of Fernando de Herrera. London: Tamesis.

Gaylord Randel, Mary (1989): "El lenguaje de la conquista y la conquista del lenguaje en las poéticas españolas del Siglo de Oro”. Edición digital a partir de las Actas del IX Congreso Internacional de Hispanistas 18-23 agosto 1986. Berlín / Frankfurt am Main: Vervuert. 469-475. <http://cvc.cervantes.es/literatura/aih/pdf/09/aih_09_1_045.pdf> [09/01/2017].

Herrera, Fernando de (1572): Relación de la guera de Cipre y sucesso de la batalla naual de Lepanto. BNE Sig. R/3794 <http://www.cervantesvirtual.com/obra/relacion-de-la-guerra-de-cipre-y-suceso-de-la-batalla-naval-de-lepanto/> [17/01/2016].

Mínguez, Victor (2011): "Iconografía de Lepanto. Arte, propaganda y representación simbólica de una monarquía universal católica”. Obradoiro de Historia Moderna 20: 255-284. 
Montero, Juan (1995): "Poesía e historia en torno a Lepanto: un ejemplo de Fernando de Herrera”. Actas del II Congreso de Historia de Andalucía. Andalucía Moderna. Edición de Junta de Andalucía, Consejería de Cultura y Medio Ambiente. Córdoba: Junta Andalucía y Cajasur. 283-289.

Montero, Juan (2007): "Relación de la guerra de Cipre y sucesso de la batalla naual de Lepanto (Sevilla, 1572): dos ediciones". "Geh hin und lerne”. Homenaje al profesor Klaus Wagner. Coord. P. Bolaños Donoso, et al. I. Sevilla: Secretariado de Publicaciones de la Universidad de Sevilla. 339-353.

Rivero Rodríguez, Manuel (2008): La batalla de Lepanto: Cruzada, Guerra Santa e identidad confesional. Madrid: Silex.

Vaca de Osma, José Antonio (1998): Carlos I y Felipe II frente a frente. Glorias, mitos y fracasos de dos grandes reinados. Madrid: Rialp. 